\title{
Percursos profissionais de pessoas doutoradas em Ciências Sociais e Humanas: o caso de Portugal
}

\author{
Heloísa Perista, Pedro Perista \& Dominique Vinck
}

\begin{abstract}
RESUMO
Apesar de ser comum afirmar-se que a integração de pessoas doutoradas fora do meio académico está a ser incentivada, a realidade demonstra que estas continuam a trabalhar maioritariamente no sector do ensino superior e da investigação. Indicam neste sentido os dados analisados neste artigo, que explora as trajetórias profissionais de mulheres e de homens com doutoramento no domínio das Ciências Sociais e Humanas (CSH), em Portugal, procurando, nomeadamente, compreender os processos que envolvem as suas experiências de mobilidade sectorial. Uma primeira fonte de informação resulta da aplicação de um questionário on-line a pessoas doutoradas em CSH. Uma segunda tem como base a realização de 25 entrevistas em profundidade a pessoas que responderam a esse questionário. Particular enfoque é dado às suas principais motivações e expetativas em termos profissionais.
\end{abstract}

\section{Palavras-chave}

Doutoramento; trajetória; percurso profissional; Ciências Sociais; Humanidades; mobilidade

\section{INTRODUÇÃo}

Detentoras de habilitações académicas superiores e de competências especializadas para a criação de conhecimento, as pessoas doutoradas reúnem potencial para desempenhar um papel importante na transferência desse mesmo conhecimento (Herrera et al., 2010; Zellner, 2003), bem como na inovação e no desenvolvimento societal, em particular quando executam atividades profissionais fora do meio académico (Cheung et al., 2012). Por isso, têm sido lançados programas destinados a aumentar o stock de capital humano dedicado à investigação e a promover a mobilidade de pessoas doutoradas (Cañibano Sánchez et al., 2011; Vinck, 1996) entre diferentes sectores (Ackers \& Gill, 2008). A revisão intercalar da "Estratégia de Lisboa para o Crescimento e o Emprego" reforçou a necessidade de combater a crise, mediante o reforço da formação de estudantes de doutoramento e a promoção de carreiras de investigação, nomeadamente através da colaboração entre os meios académico e empresarial (Comissão Europeia, 2011). A intensificação da mobilidade das pessoas doutoradas e a melhoria das suas perspetivas de carreira têm sido encaradas como eixos facilitadores da sua integração em diferentes sectores (Cruz Castro \& Sanz Menéndez, 2005; Fritsch \& Krabel, 2012; Thune, 2009).

Ainda que as políticas públicas procurem aumentar o stock de capital humano com habilitações superiores, a empregabilidade destas pessoas fora do meio académico nem sempre é evidente. A atratividade desses empregos é limitada (Enders, 2002), entre outros motivos porque quem possui um doutoramento sofre, amiúde, a frustração de ser 
considerado/a sobrequalificado/a para determinados cargos, especialmente na área das Ciências Sociais e Humanas (CSH) (Calmand \& Giret, 2010). Como tal, estas pessoas continuam a ter, predominantemente, atividades profissionais em áreas ligadas ao ensino superior e à investigação realizada no sector público (Auriol et al., 2013). Quando abandonam o mundo académico, tal deve-se, principalmente, a motivos, tais como a elevada concorrência para um número reduzido de vagas (Fox \& Stephan, 2001), a escassez de lugares de quadro (Barnacle \& Dall'Alba, 2011), os baixos salários auferidos na academia (Stephan \& Levin, 1997), a limitada atratividade de uma carreira académica (Huisman et al., 2002) e o aumento da instabilidade dos contratos de trabalho (Horta, 2009).

Quando se fala em mobilidade de pessoas doutoradas, é mais comum pensar-se nas Ciências Naturais e na Engenharia. Estudos anteriores que consideram a possibilidade destas pessoas conseguirem trabalho fora do mundo académico (Auriol, 2010; Cyranoski et al., 2011; Lee, Miozzo \& Laredo, 2010; Yerkes et al., 2012) referem essas áreas, em concreto. No entanto, há diferenças significativas entre disciplinas (Fritsch \& Krabel, 2012). Onde estão as pessoas doutoradas em CSH? Até há muito pouco tempo, pouco se conhecia sobre os seus percursos profissionais, uma vez que estas áreas são perspetivadas, muitas vezes, como menos importantes para a economia. Além disso, as pessoas com doutoramento na área das Humanidades e em comparação com os colegas de outras disciplinas, consideram frequentemente o trabalho no sector privado como sendo menos atrativo. Adicionalmente, quando trabalham para uma empresa privada, sentem-se mais frustradas no que se refere às recompensas que obtêm pelos seus esforços intelectuais (Canal \& Wall, 2014). No fundo, a atividade em meio académico continua desencadear níveis mais elevados de satisfação no trabalho.

Em Portugal, até há relativamente pouco tempo, as pessoas com doutoramento, em particular na área das $\mathrm{CSH}$, integravam-se, tradicionalmente e quase exclusivamente, no meio académico. Era comum, aliás, encarar-se o doutoramento como o auge de uma carreira académica, o culminar de anos (décadas) de investigação.

Contudo, os anos 2000 testemunharam alterações importantes, nomeadamente devido ao surgimento de um novo enquadramento da carreira de docente universitário/a, estabelecido pelo DecretoLei 205/2009 de 31 de agosto, que determinou o doutoramento como requisito mínimo para lecionar no ensino superior.

Entre 2000 e 2010, 5164 pessoas obtiveram um doutoramento em $\mathrm{CSH}$, mais do dobro das 2285 pessoas que se doutoraram em CSH entre 1970 e 1999. Só em 2011 e 2012, 1711 pessoas concluíram um doutoramento na área das Ciências Sociais e Humanas. No entanto, o mundo fora da academia continuou a demonstrar poucos sinais de interesse no potencial de experiência decorrente da expansão do número de pessoas doutoradas em CSH. Ainda assim, foi-se tornando mais comum encontrar pessoas detentoras de um doutoramento em CSH noutros sectores que não o académico.

O objetivo principal deste artigo é analisar a trajetória de pessoas doutoradas em $\mathrm{CSH}$ em Portugal, respondendo a uma lacuna no que diz respeito ao conhecimento sobre os seus percursos e perspetivas profissionais. Seguindo as suas trajetórias, procuramos, também, evidenciar os processos que envolvem as suas mudanças de perspetivas, 
expetativas e empregos, ao longo dos seus percursos de carreira, especialmente no que diz respeito à decisão de trabalhar dentro ou fora do meio académico e às razões e condições subjacentes a eventuais mudanças.

\section{UM QUESTIONÁRIO E ENTREVISTAS EM PROFUNDIDADE}

Este artigo baseia-se numa pesquisa financiada pelo sétimo programa-quadro de apoio a projetos de investigação, da União Europeia, no âmbito do projeto POCARIM (Mapping the Population, Careers, Mobilities and Impacts of Advanced Research Degree Graduates in Social Sciences and Humanities)'. No âmbito deste projeto considerou-se que as $\mathrm{CSH}$ abrangem as seguintes áreas: Arqueologia, História, Línguas, Literatura, Filosofia, Ética, Religião e outras áreas classificadas como Humanidades; Antropologia, Etnologia, Demografia, Ciências Da Educação, Comunicação Social, Ciência Política, Incluindo Administração Pública e Relações Internacionais, Psicologia, Geografia Económica e Social, Geografia Humana, Sociologia e outras áreas das Ciências Sociais; e, por fim, Economia, Ciências Empresariais, Gestão e Direito.

Numa primeira etapa, reuniu-se um conjunto de dados a partir de um questionário online, disponibilizado em inglês e em cada um dos idiomas nacionais, através do software SelectSurvey. Net, a pessoas doutoradas em CSH de 13 países europeus (França, Alemanha, Hungria, Itália, Letónia, Noruega, Polónia, Portugal, Eslováquia, Espanha, Suíça, Turquia e Reino Unido). O questionário foi dirigido a pessoas que tivessem obtido o grau de doutoramento entre 2000 e 2012, tendo coberto uma amostra equilibrada em termos da abrangência de várias áreas das CSH, vários sectores laborais e diferentes instituições de ensino em diferentes regiões. O conjunto de respostas foi recodificado, verificado e limpo. Em Portugal, foram obtidas 175 respostas válidas ao questionário.

Numa segunda etapa, foram conduzidas em Portugal, 25 entrevistas em profundidade a pessoas que tinham assinalado a sua disponibilidade para virem a ser entrevistadas na sequência da sua resposta ao questionário. O guião de entrevista cobriu diferentes temas relacionados com as trajetórias profissionais e os processos a estas subjacentes: a situação pré-doutoral e a sua relação com o doutoramento; a formação doutoral e as expetativas associadas a esta; a atividade profissional após o doutoramento, incluindo estratégias de procura de emprego; a importância das competências doutorais; a motivação; as várias formas de mobilidade e o estabelecimento de redes de contatos; questões linguísticas; a interdisciplinaridade; o impacto do conflito do trabaIho com a vida familiar, etc. Tendo a duração aproximada de uma hora, cada entrevista foi gravada, transcrita na totalidade e codificada com o auxílio do programa NVivo.

No âmbito deste artigo, a análise dos dados centra-se no sector de emprego das pessoas respondentes, no respetivo percurso profissional, no momento e na forma como estabeleceram relações com o mundo não académico e na tipologia dos passos encetados, com o objetivo de perceber a dinâmica subjacente a esses passos. $\mathrm{O}$

' Mais informação em http://www.salford.ac.uk/nmsw/research/research-projects/pocarim-home. Também pode ser consultada outra informação em http://cordis.europa.eu/result/rcn/169013_en.html. 
percurso de cada pessoa foi caraterizado e codificado de forma a poder ser traduzido na série de etapas e de mudanças de direção respetivas. Os resultados foram processados com recurso ao Excel, Gephi e TraMineR, de modo a produzir-se uma visão de síntese.

\section{Percursos profissionais e motivadores de mudança}

Das pessoas que responderam ao questionário, $53,5 \%$ eram do sexo masculino e $46,5 \%$ do sexo feminino. A maioria (54,3\%) obteve o doutoramento entre 2009 e 2012 , conferindo à amostra um perfil de doutoramento recente. Cerca de $90 \%$ obtiveram o grau entre 2003 e 2012. A amostra era composta por pessoas doutoradas essencialmente das áreas disciplinares especificadas abaixo (Tabela 1).

\begin{tabular}{lc}
\hline \multicolumn{1}{c}{ ÁREAS CIENTífICAS } & $\begin{array}{c}\text { INQUÉRITO } \\
\text { (PERC.) }\end{array}$ \\
\hline Ciências económicas e empresariais & 18,9 \\
\hline Sociologia & 15,4 \\
\hline Ciências da educação & 11,4 \\
\hline Línguas e literaturas & 9,7 \\
\hline Psicologia & 9,7 \\
\hline História & 8,0 \\
\hline Direito & 5,7 \\
\hline Geografia económica e social & 4,0 \\
\hline Filosofia, ética e religião & 3,4 \\
\hline Arqueologia & 3,4 \\
\hline Outra $\quad$ Tabela 1: Composição da amostra do inquérito \\
\hline \multicolumn{2}{c}{$\quad$ Fonte: Inquérito por questionário }
\end{tabular}

Cerca de duas em cada três pessoas inquiridas eram doutoradas nas áreas das Ciências Económicas e Empresariais, Sociologia, Ciências da Educação, Línguas e Literaturas e Psicologia. As mulheres estavam, em maioria, nas Ciências Económicas e Empresariais $(56,3 \%)$, Línguas e Literatura (58,8\%), Sociologia $(69,2 \%)$ e Psicologia $(81,3 \%)$. Os inquiridos do sexo masculino apenas representavam a maioria na subárea das Ciências da Educação (55\%).

No que diz respeito ao emprego, a grande maioria (96\%) das pessoas inquiridas tinha um emprego remunerado (sendo as bolsas de investigação incluídas nesta categoria). Das que estavam empregadas, $84,1 \%$ trabalhavam no sector público e $12,9 \%$ no sector privado. Cerca de $92 \%$ desenvolviam a sua atividade no ensino superior e/ou na investigação. A situação portuguesa é semelhante à registada pelo inquérito europeu ( $87 \%$ no sector público, $7 \%$ no sector privado e $2 \%$ no terceiro sector), embora deva salientar-se o "reforço" do sector privado na amostra nacional.

Relativamente aos percursos profissionais, imediatamente após a obtenção do doutoramento, $53,6 \%$ das pessoas ficaram integradas num emprego de carácter permanente ${ }^{2}$.

\footnotetext{
${ }^{2}$ É importante ter em atenção que esta colocação era, em muitos casos, anterior à obtenção do doutoramento.
} 
Aos inquiridos do sexo masculino foi-lhes ligeiramente mais fácil a integração num emprego permanente em comparação com as inquiridas (56,8\% face a $52,7 \%$ ). Em ambos os casos, a situação profissional vivida no momento da entrevista era menos estável (56,1\% dos homens tinham emprego permanente, face a $50 \%$ das mulheres), situação a que não será alheia a instabilidade causada pela crise económico-financeira.

O principal factor diferenciador a este nível é o ano de obtenção do doutoramento. Aproximadamente duas em cada três pessoas que se doutoraram até 2009 conseguiram uma atividade de tipo permanente. Entre quem se doutorou no intervalo de 2010 e 2012, a percentagem é inferior a $37 \%$.

É importante verificar que, entre quem obteve o doutoramento entre 2000 e 2009 , mais mulheres $(69,2 \%)$ do que homens $(63 \%)$ ficaram num emprego de caráter permanente. Em contrapartida, entre 2010 e 2012 a situação foi inversa: 30,8\% das mulheres, face a $46,4 \%$ dos homens.

$\mathrm{Na}$ quase totalidade dos casos $(98,2 \%)$, as pessoas inquiridas não registaram qualquer mudança de sector. A grande maioria das pessoas inquiridas $(91,8 \%)$ trabalhou sempre numa instituição de ensino superior ou de investigação. 97,1\% das pessoas com atividade profissional no setor público após a obtenção do doutoramento permaneceram nessa posição.

Embora a maioria daqueles/as cuja primeira colocação profissional aconteceu no setor privado após a obtenção do doutoramento tenha permanecido nesse sector, é de realçar que aproximadamente um/a em cada cinco mudou para o sector público.

A combinação destes resultados demonstra que, num quadro global de imobilidade, as poucas mudanças ocorridas respeitaram, sobretudo, a profissionais que passaram de uma instituição de ensino superior ou de investigação privada para uma instituição pública com as mesmas características.

\section{DinÂMICAS SUBJACENTES}

As entrevistas realizadas proporcionaram um melhor conhecimento sobre as expetativas e percursos antes e durante a tese de doutoramento, bem como durante a primeira colocação após o doutoramento e a situação de emprego no momento da entrevista. Tendo em conta cada uma destas etapas, a análise das entrevistas permitiu caraterizar a direção da mudança pretendida e os motivos para iniciar ou manter uma carreira académica relativamente às mudanças de direção previstas. Elaboram-se uma tabela (Tabela 2) e um gráfico (Figura 1) com o resumo dos percursos profissionais do conjunto de pessoas doutoradas em CSH entrevistadas em Portugal, no que se refere às seguintes etapas:

Etapa 1. Foram observados quatro tipos de situação pré-tese de doutoramento:

- No meio académico: enquanto estudante, a pessoa respondente já tinha decidido seguir carreira no mundo académico; realizar uma tese de doutoramento era, assim, um ponto de passagem obrigatório.

- Próximo do meio académico: enquanto estudante, a pessoa respondente não tinha planos profissionais claros; iniciou um doutoramento porque pensava que poderia gostar de trabalhar em 
investigação ou apenas para ter a oportunidade de fazer investigação sem quaisquer expectativas específicas.

- Investigação fora do meio académico: a pessoa respondente pretendia mudar as suas perspetivas mas não via o mundo académico como um futuro possível.

- Fora da área da investigação: sem ligação à investigação e ao meio académico, a pessoa respondente pretendia melhorar as suas competências, sem necessariamente esperar vir a trabalhar no mundo académico.

\section{Etapa 2. Confirmação ou mudança de direção durante a tese:}

- No meio académico: a pessoa respondente descobriu ou confirmou a sua vocação para a investigação e esperava construir uma carreira na investigação académica.

- Próximo do meio académico: a pessoa respondente descobriu um novo mundo fora do contexto académico, mas prosseguiu com a carreira académica.

- Investigação fora do meio académico: a pessoa respondente descobriu um novo mundo fora do meio académico e começou a considerar seriamente uma carreira não académica.

- Fora da área da investigação: a pessoa respondente confirmou a pretensão de trabalhar fora do meio académico.

\section{Etapa 3. Primeira colocação profissional após a tese de doutoramento:}

- No meio académico: a pessoa respondente trabalhou no mundo académico com a intenção de aí permanecer.

- Próximo do meio académico: a pessoa respondente trabalhou no mundo académico, mas manteve um posto de trabalho instável ou à margem e ambicionou ocupar um posto permanente ou a tempo inteiro.

- Investigação fora do meio académico: a pessoa respondente trabalhou em investigação fora do contexto académico.

- Fora da área da investigação: a pessoa respondente trabalhou fora do mundo académico, com possibilidade de ter mantido ligações com o mesmo.

Etapa 4. Situação de emprego no momento da entrevista (mesmas categorias da etapa 3).

\begin{tabular}{|c|c|c|c|c|}
\hline Percurso / tem po & $\begin{array}{c}\text { ANTES DO } \\
\text { DOUTORAMENTO }\end{array}$ & $\begin{array}{c}\text { DURANTE O } \\
\text { DOUTORAMENTO }\end{array}$ & $\begin{array}{l}\text { PRIMEIRO } \\
\text { EMPREGO }\end{array}$ & $\begin{array}{l}\text { EMPREGO } \\
\text { ATUAL }\end{array}$ \\
\hline Fora da área da investigação & $12 \%(3)$ & $4 \%(1)$ & $16 \%(4)$ & $20 \%(5)$ \\
\hline Fora do meio académico & $4 \%(1)$ & $4 \%(1)$ & $8 \%(2)$ & $4 \%(1)$ \\
\hline Próximo do meio académico & $28 \%(7)$ & $36 \%(9)$ & $68 \%(17)$ & $40 \%(10)$ \\
\hline No meio académico & $56 \%(14)$ & $56 \%(14)$ & $8 \%(2)$ & $36 \%(9)$ \\
\hline TOTAL & $100 \%(25)$ & $100 \%(25)$ & $100 \%(25)$ & $100 \%(25)$ \\
\hline
\end{tabular}

Tabela 2: Transições entre etapas da carreira

Fonte: Inquérito por questionário 


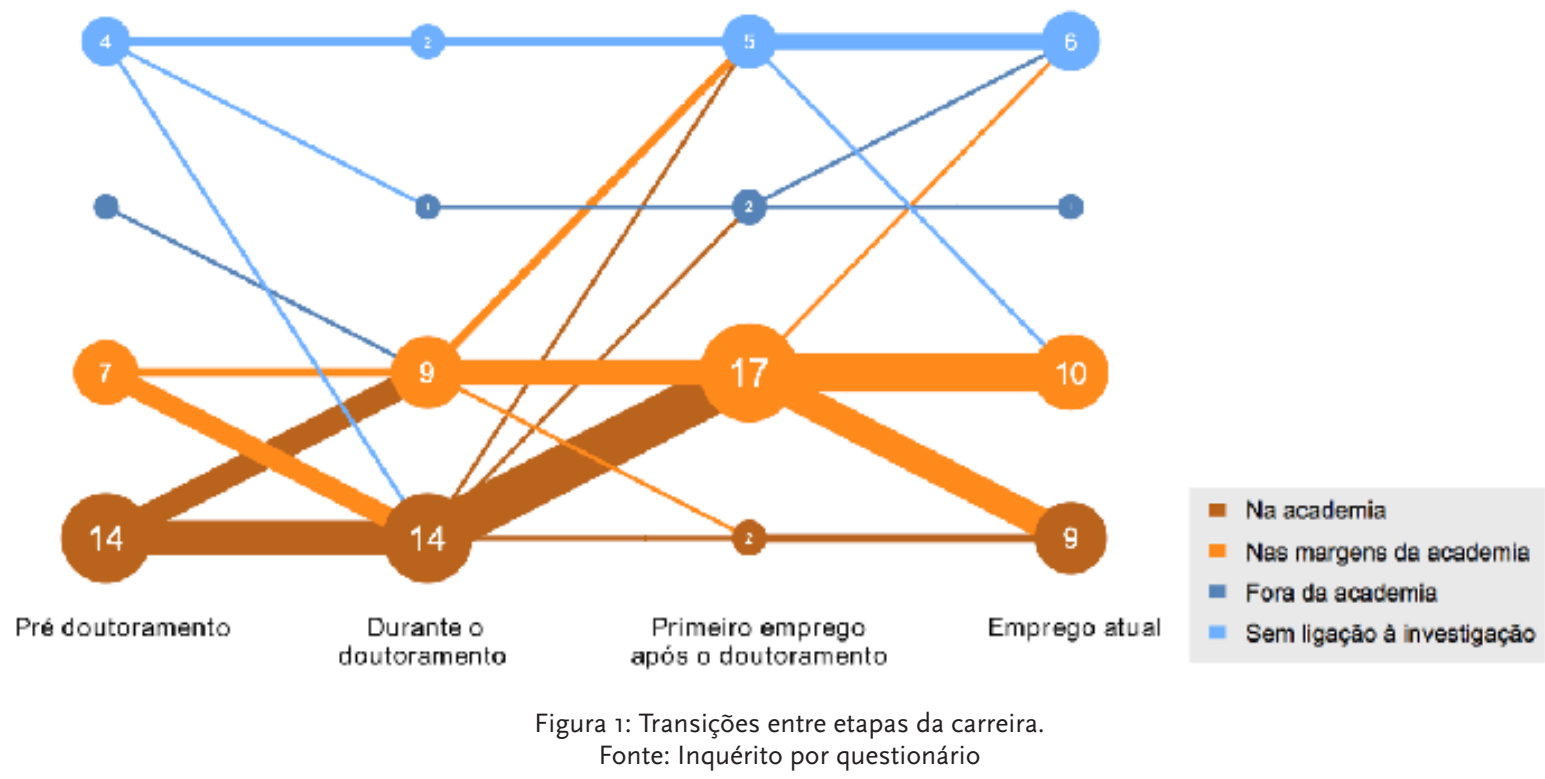

Antes de realizar a sua tese de doutoramento, $56 \%$ das pessoas inquiridas esperavam obter o grau como forma de entrar ou progredir no meio académico. Para estas, a tese de doutoramento foi entendida com um ponto de passagem obrigatório:

P: Optou por realizar um doutoramento ou este foilhe imposto pela carreira na universidade?

R: Foi um pouco dos dois. Foi uma opção, não tanto pelo doutoramento, mas pela carreira. $O$ doutoramento serviu de instrumento para progredir na carreira.

( $\mathrm{PT} 1$ - no meio académico, homem, 45 anos de idade)

O doutoramento foi obrigatório na minha carreira. Ou obtinha um doutoramento ou abandonava a universidade. (PT5 - no meio académico, mulher, 43 anos)

Isto significa que uma minoria considerável (44\%) não pretendia seguir, à partida, uma carreira académica. Um grupo significativo (28\%) compõem-se de quem estudou sem nenhum plano profissional claro. Estas pessoas iniciaram um doutoramento, ou porque se interessavam por investigação, ou porque, tendo tido um bom desempenho escolar, foram aconselhadas por um/a professor/a a realizar uma tese de doutoramento. Este foi o caso de uma estudante de mestrado em França:

Quando a minha tese de mestrado estava prestes a ser avaliada, o meu orientador principal disseme que eu tinha capacidade para um doutoramento. Não é como em Portugal, onde uma pessoa se candidata a um doutoramento. Ali, o doutoramento parte de um convite. Foi assim que fiz um doutoramento; porque a minha ideia inicial era um mestrado. (PT3 fora da área da investigação, mulher, 37 anos) 
Para outras pessoas, o que abriu caminho para o doutoramento foi o interesse em investigação combinado com a possibilidade de participar num projeto de investigação:

Quando estava na licenciatura, gostava de todos os trabalhos de investigação e sentia-me entusiasmada. Quando a concluí, fiquei interessada em tirar um mestrado (...). A ideia do mestrado surgiu porque queria aprender mais e a ideia de fazer investigação durante o mestrado entusiasmava-me. Entretanto, quando entrei no mestrado, foi aprovado um projeto da FCT à pessoa que me orientava, [nome da pessoa], e havia duas bolsas para investigadores. (...) Quando entrei no projeto, foi colocada a hipótese de escrever uma dissertação de mestrado como extensão do mesmo. Tudo começou muito bem e estava entusiasmada com o projeto. A dada altura, surgiu a ideia de pedir transferência. Na verdade, nunca terminei o mestrado; fiz o primeiro ano, pedi equivalência para o primeiro ano do doutoramento e entrei no doutoramento. (...) Para ser sincera, não pretendia ser professora universitária; de facto, durante algum tempo, não era sequer um objetivo. Eu queria apenas fazer investigação e aprender mais. Quando estava na licenciatura, senti que precisava de saber mais; no mestrado, senti que podia fazer mais e, por fim, no doutoramento, senti que podia aprender mais e continuei sempre. (PT16 - em meio académico, mulher, 37 anos)

Noutros casos, tinham interesse no assunto em que estavam a trabalhar e quiseram aprofundá-lo, sem ter necessariamente expetativas específicas em termos profissionais. As suas razões eram sobretudo intelectuais; eram motivados/as pelo entusiasmo e paixão por um tema de investigação. Este foi o caminho seguido por um cidadão italiano que veio para Portugal a fim de prosseguir os estudos em Filosofia e já com o intuito adicional de um dia entrar no meio académico. À data da entrevista, estava a realizar um pós-doutoramento:

Motivou-me o interesse pela área e a vontade de continuar a trabalhar em Filosofia. Não é uma área que ofereça muitas opções... Pode servir de preparação para outras carreiras, mas se o objetivo for continuar a estudar Filosofia e trabalhar nesta área, é quase obrigatório seguir uma carreira académica. Quando terminei a licenciatura, ainda estava muito motivado para continuar nesta área. Por isso, a ideia de iniciar o doutoramento era a de prosseguir e aprofundar o que tinha começado na minha tese de licenciatura. (PT6 - próximo do meio académico, homem, 42 anos)

Um terceiro grupo (16\%) abrange quem já se encontrava empregado/a. As pessoas integrantes deste grupo tinham motivos diferentes para fazer o doutoramento, mas não estavam sem ambições académicas. Uma investigadora a trabalhar em contexto não académico obteve o doutoramento para cumprir os requisitos da carreira em investigação e das entidades de financiamento nacional: 
P: Quais foram os principais motivos para fazer um doutoramento? $\mathrm{R}$ : Os motivos foram mais profissionais do que pessoais. Nuncatinha pensado em inscrever-me num doutoramento. Porém, a dada altura, começaram a surgir cada vez mais requisitos, principalmente relacionados com financiamento nacional, para que as candidaturas a projetos incluíssem pessoas doutoradas. (PT2 - em investigação fora do meio académico, mulher, 49 anos)

Outro entrevistado, com 51 anos de idade, obteve o doutoramento em 2011. Este doutorado considera que a obtenção do grau lhe garantiu mais possibilidades de continuar a lecionar numa universidade privada. Todavia, não tinha outras expetativas relacionadas com a conclusão da tese no que diz respeito à sua atividade profissional principal (trabalhador independente no sector privado em atividade não relacionada com investigação). Em qualquer caso, considera o doutoramento uma oportunidade de ampliar conhecimentos e competências científicas.

A realização e o desenvolvimento pessoal também constituíram focos de motivação para outras pessoas respondentes. É o caso de um professor do ensino secundário que concluiu o doutoramento em 2007, já perto dos 50 anos de idade:

Sou professor do ensino secundário, pelo que a decisão de fazer um doutoramento foi apenas uma questão de realização pessoal. Não foi uma decisão relacionada com a minha carreira profissional. (...) Na minha área, história, a probabilidade de trabalhar em qualquer instituto [politécnico], mesmo que durante pouco tempo, é muito reduzida. Como tal, o doutoramento foi uma questão de realização pessoal. (PT21 - fora da área da investigação, homem, 54 anos)

Este grupo não procurou, portanto, um doutoramento necessariamente com o intuito de seguir uma carreira académica. Trata-se de um resultado consistente com estudos anteriores sobre estudantes de doutoramento em $\mathrm{CSH}$ e as suas motivações (Brailsford, 2010; Guerin et al., 2014; Leonard et al., 2005; Roach \& Sauermann, 2010).

Porém, em alguns casos, ocorrem mudanças de orientação durante a tese de doutoramento. Algumas das pessoas entrevistadas (24\%) começaram a considerar a hipótese de uma carreira académica, descobrindo ou confirmando a sua intenção de continuar a trabalhar em investigação no meio académico. O caso de uma consultora em planeamento regional com um posto de trabalho estável, mas que decidiu obter um doutoramento, ilustra este tipo de mudanças durante a tese:

Nunca tive a ambição de seguir uma carreira académica, nunca! Sou muito pragmática e a pesquisa não combinava com a minha forma de ser. A minha licenciatura era em planeamento e foi isso que aprendi a fazer: dar respostas rápidas a problemas reais. Como tal, isto da investigação, de querer saber muita teoria, era algo que nem sequer se enquadrava na minha personalidade. Assim sendo, no início, tive muitos problemas em conjugar tudo. (...) Agora, aprendi a gostar de investigação e tenho pena de não 
poder dedicar-me a isso. (...) de facto, apaixonei-me pela investigação por si só. Pela teoria, pelo desenvolvimento científico. Tornei-me numa pessoa que antes não era. Tornei-me muito mais curiosa. (PT11 - fora da área da investigação, mulher, 36 anos)

Outros $32 \%$ consideraram seguir uma carreira académica durante o período de realização da tese, mesmo tendo tido contato com o mundo fora da academia e estando preparados/as para abandonar o meio académico, se necessário. $56 \%$ das pessoas respondentes consideraram seriamente uma carreira académica durante o período de realização da tese. Os/as restantes (44\%) descobriram outro mundo fora do ambiente universitário e começaram, ou a considerar seriamente uma carreira não académica (36\%), ou a planear trabalhar fora da academia (8\%).

Porém, após a conclusão do doutoramento, apenas $4 \%$ conseguiram postos de trabalho permanentes no meio académico. A maioria das pessoas respondentes (68\%) tinha, nessa altura, empregos instáveis no meio académico. Empenhados/as em seguir uma carreira académica, encontraram emprego neste meio, embora em condições mais instáveis (por exemplo, com contratos de investigação ou em postos temporários de ensino) ou marginais (por exemplo, cargos administrativos no sector do ensino superior e da investigação). Contudo, o doutoramento trouxe, nalguns casos, melhorias em relação à estabilidade do emprego e à remuneração. Foi o caso de um entrevistado, professor de uma grande universidade privada:

Antes, durante e depois do doutoramento, sempre fui professor na mesma universidade. A única melhoria ocorreu depois de terminar o doutoramento, há menos de um ano, quando a faculdade me ofereceu um contrato um pouco melhor do que o anterior. Trabalhei a recibos verdes durante cerca de oito anos. Como esta situação era precária, era obrigado a trabalhar na área da música, além de desenvolver o doutoramento. Foi difícil em termos de gestão de tempo. Quando concluí o doutoramento, como consequência, e talvez não só, foi-me oferecido um contrato temporário. Ainda assim, era um contrato temporário e não permanente. Mas, pelo menos, agora tenho um salário mensal. (PT4 - no meio académico, homem, 31 anos)

Um número muito reduzido de pessoas encontrou um emprego em investigação fora do meio académico. Outras mantiveram um emprego no ensino secundário, em empresas, em consultoria, na administração pública ou em ONGs. No entanto, quando as pessoas deste grupo foram entrevistadas, a maioria mantinha contato com o mundo académico: eram docentes na universidade para além da sua atividade principal; continuavam a fazer investigação em colaboração com a academia; recrutavam estudantes de doutoramento para as suas empresas e eram coorientadores/as nas teses; publicavam artigos, por vezes, como coautores/as em colaboração com académicos/as, mesmo que a investigação não fizesse parte do seu quotidiano de trabalho.

Alguns anos após o doutoramento, $36 \%$ das pessoas entrevistadas encontraram postos de trabalho mais estáveis no meio académico. 
Quando concluí o doutoramento tornei-me automaticamente professora auxiliar com um contrato de cinco anos. Quando este terminar, é possível que tente obter um contrato permanente. É neste ponto em que me encontro. Acabei de obter uma nomeação definitiva, com base na análise do CV e em dois pareceres, após aprovação pela Comissão Científica da Universidade. (PT10 - no meio académico, mulher, 40 anos)

Outras $40 \%$ mantiveram postos de trabalho marginais e/ou instáveis no meio académico, mas continuaram a aspirar a uma carreira neste meio, apesar de, em alguns casos, a confiança ir esmorecendo. Algumas pessoas permaneceram no meio académico, mesmo quando as condições e perspetivas de trabalho eram más. Entre as pessoas com empregos fora da área da investigação (20\%), apenas $8 \%$ estiveram sempre fora da academia. As restantes acabaram por mudar de direção no decorrer do percurso profissional.

Quem abandonou o mundo académico refere que o motivo para tal se deveu ao término do contrato de trabalho ou à procura de melhores oportunidades profissionais. Porém, os motivos para abandonar o meio académico variaram de acordo com a experiência de trabalho fora deste meio durante ou após o doutoramento. Por exemplo, quem tinha experiência na administração pública ou em empresas demonstrava mais probabilidade de vir a sair do meio académico.

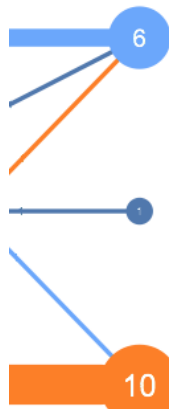

10

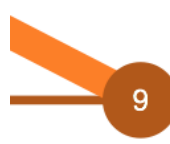

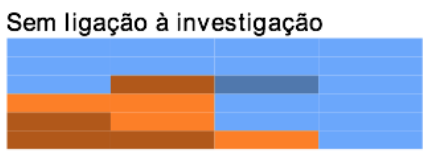

Fora da academia

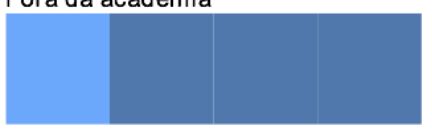

Nas margens da academia

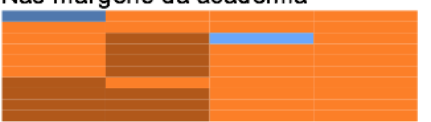

$\mathrm{Na}$ academia

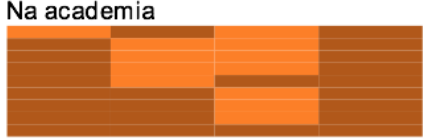

Emprego atual

Figura 2: Transições entre etapas da carreira das pessoas respondentes, classificadas com base no emprego atual.

Fonte: Inquérito por questionário

O caso da entrevistada que começou a carreira como consultora privada e foi para a universidade durante vários anos com o objetivo de obter um doutoramento tendo, após a respetiva conclusão e contra a sua vontade, deixado o mundo académico, merece uma menção especial: 
Defendi a minha tese de doutoramento no dia 10 de maio de 2010, numa sexta-feira à tarde. Na segunda-feira seguinte foi-me dito que me tinha tornado num recurso demasiado dispendioso para a instituição que me concedera o diploma. Obviamente, falo disto com pena. Tive de fazer uma escolha. Uma opção era ficar e esperar por melhores dias, estando sujeita a tarefas que não eram compatíveis com as minhas habilitações. Não aceitei esta opção, uma vez que conhecia bem a instituição e sabia que havia condições para me oferecerem mais. O problema não se prendia com as minhas habilitações, mas provavelmente com outros motivos que não me foram explicados. Foi curioso ter recebido um convite de um professor, com quem tinha mantido contacto durante o doutoramento, mas não recentemente, para integrar o grupo de investigação mencionado. Pensei que era uma coincidência muito grande, mas aceitei. Isto aconteceu em maio de 2010 e foi até fevereiro de 2011; quando comecei a trabalhar aqui, não exercia uma atividade profissional de cariz formal. Fui integrada no centro como colaboradora, uma vez que é a única forma para um doutorado ser integrado. Eu estava interessada, porque integrei um centro, e eles tinham interesse porque tinham mais uma pessoa doutorada, condição importante em termos de atribuição de fundos pelo ministério. Volto a dizer, apenas como colaboradora. Colaborei em três ou quatro candidaturas sem ser remunerada. Entretanto, trabalhei como consultora num município e fiz candidaturas para uma empresa em [nome da localidade], sendo estas as minhas fontes de rendimentos. Engravidei, o meu filho nasceu em agosto e decidi que esta situação era demasiado instável, pelo que decidi procurar outras opções. A minha candidatura para a [entidade pública relacionada com o ensino superior] resultou de um anúncio no jornal. Fiz a candidatura, passei pelos procedimentos normais, duas entrevistas e um teste, e fui admitida. E aqui estou! (PT11 - fora da área da investigação, mulher, 36 anos)

Ainda no que diz respeito às trajetórias, foi possível verificar que a larga maioria $(89 \%)$ das pessoas que estavam num posto de trabalho permanente tinha a expectativa, já durante a realização da sua tese, de vir a consegui-lo, embora estando aberta a outras possibilidades. Por vezes, começaram em postos de trabalho mais instáveis. $50 \%$ das pessoas que ou continuavam, no momento da entrevista, num posto de trabalho instável na academia ou se encontravam nas margens do meio académico não mostraram expectativas específicas sobre a possibilidade de uma carreira académica. Outras 40\% esperavam poder seguir uma carreira académica.

As que estavam a trabalhar fora do meio académico ou da área de investigação ambicionavam outras perspetivas, antevendo serem a investigação ou o meio académico possíveis espaços de trabalho, no futuro (50\%). Essas perspetivas acabaram por não ser concretizadas. Uma minoria (20\%) daquelas que se encontravam a trabalhar fora 
do meio académico ou da área de investigação esperava seguir uma carreira académica, mas mudou de ideias durante a tese ou durante a sua primeira experiência profissional pós-doutoramento.

No que diz respeito a diferenças de género, homens e mulheres partilhavam perfis semelhantes relativamente a expetativas antes da tese de doutoramento, embora existissem mais homens fora do meio académico (Figura 3). Durante o doutoramento, não se observam alterações. No enanto, apenas os homens tenham tido como primeiro emprego postos de trabalho académicos permanentes $(8 \%)$. Porém, alguns anos após a conclusão do doutoramento, mais mulheres (24\%), tinham obtido um cargo permanente no meio académico.
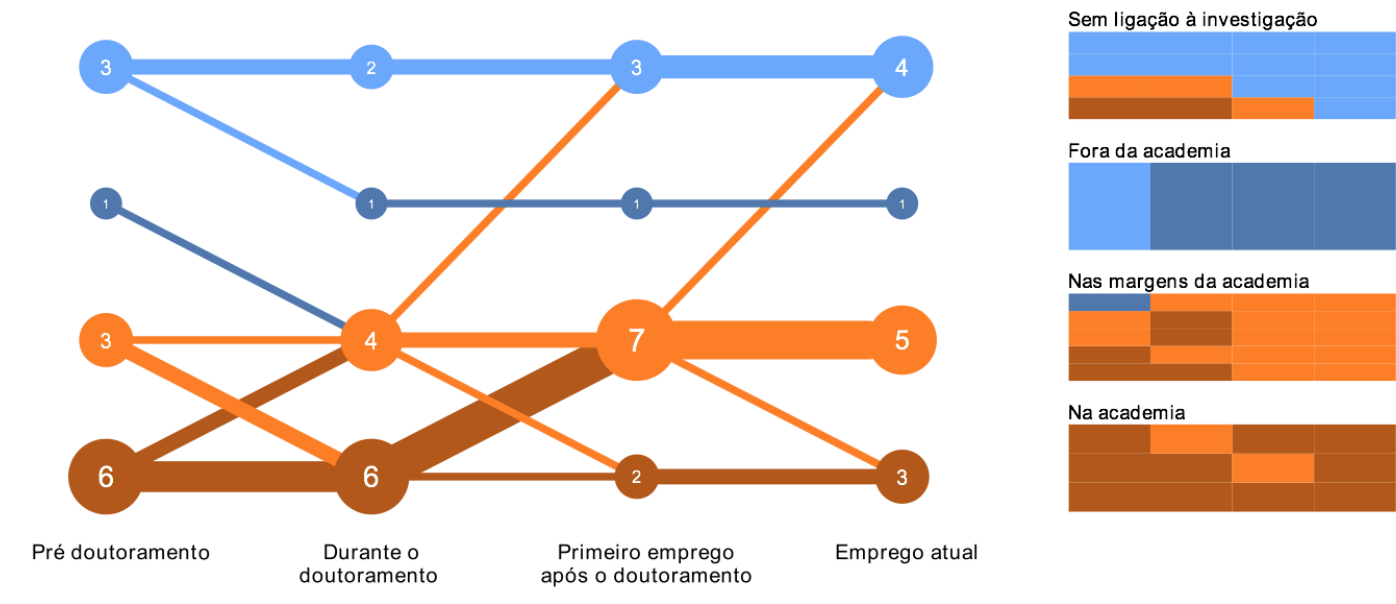

Nas margens da academia

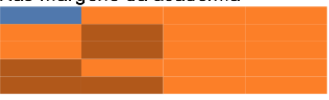

Na academia
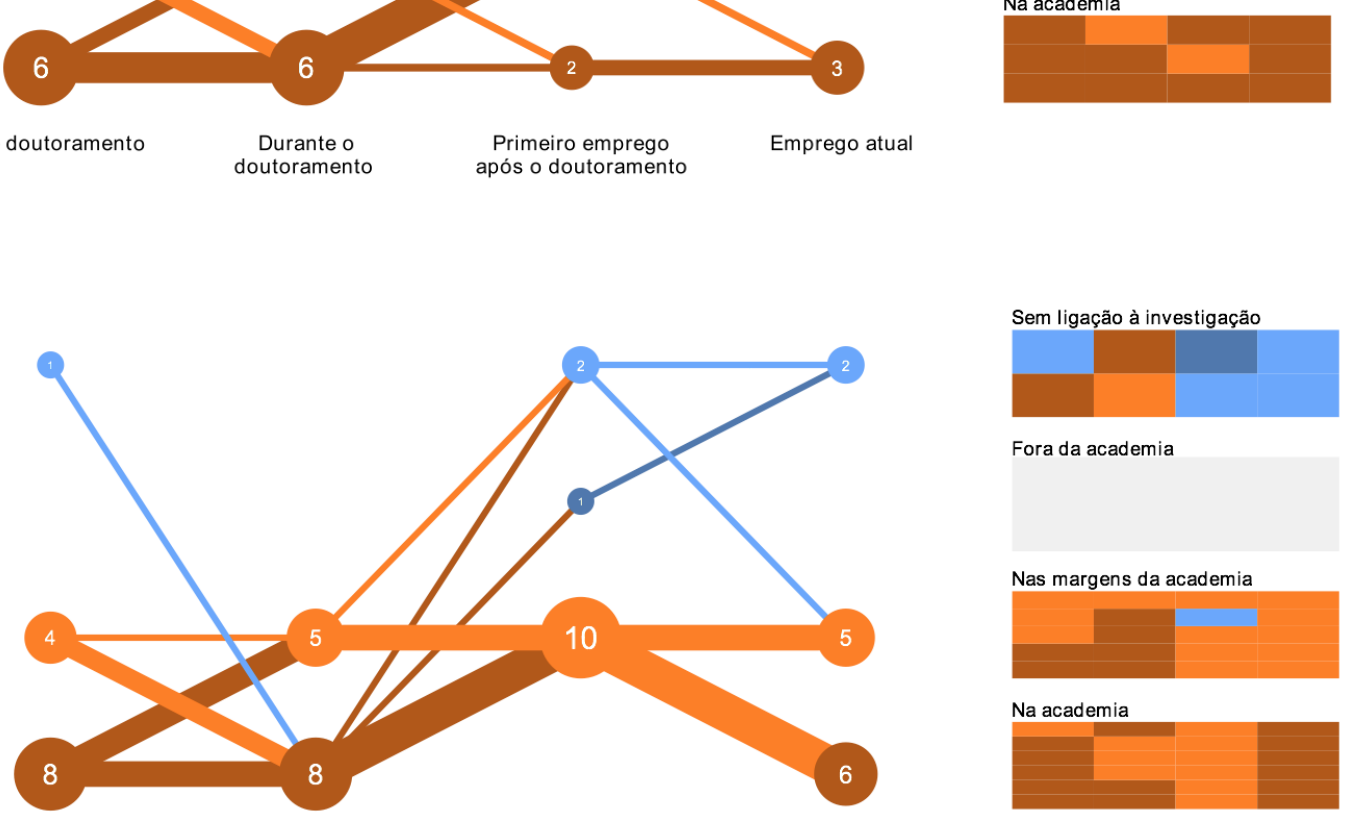

Primeiro emprego após o doutoramento
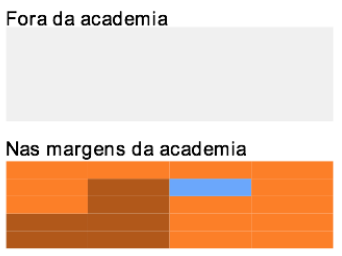

$\mathrm{Na}$ academia

Pré doutoramento

Durante o doutoramento

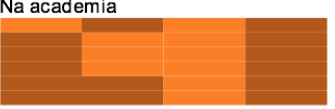

Emprego atual

Figura 3: Transições entre etapas da carreira das pessoas respondentes do sexo masculino e do sexo feminino.

Fonte: Inquérito por questionário

No que diz respeito a diferenças entre áreas disciplinares, registam-se dois padrões distintos nas Humanidades: um marginal, respeitante a quem pretendia prosseguir carreira fora do meio académico; e um dominante, relativo a quem tinha a expetativa de construir uma carreira académica. Esta situação apenas se veio a concretizar, todavia, para um terço daqueles/as que a planeavam antes ou durante a tese (Figura 4a). 
Nas Ciências Sociais, o fluxo principal concentrase na expetativa de seguir uma carreira académica antes ou durante o doutoramento, mas com um fluxo progressivo de desistências a favor de empregos fora da área da investigação e com um padrão de pessoas doutoradas com uma primeira colocação instável no meio académico antes de se estabilizarem no mesmo.

$\mathrm{Na}$ área da Economia, Ciências Empresariais e Direito, as quatro pessoas respondentes apresentavam percursos profissionais distintos, mas todas se enquadravam no meio académico, num emprego permanente, ou não.

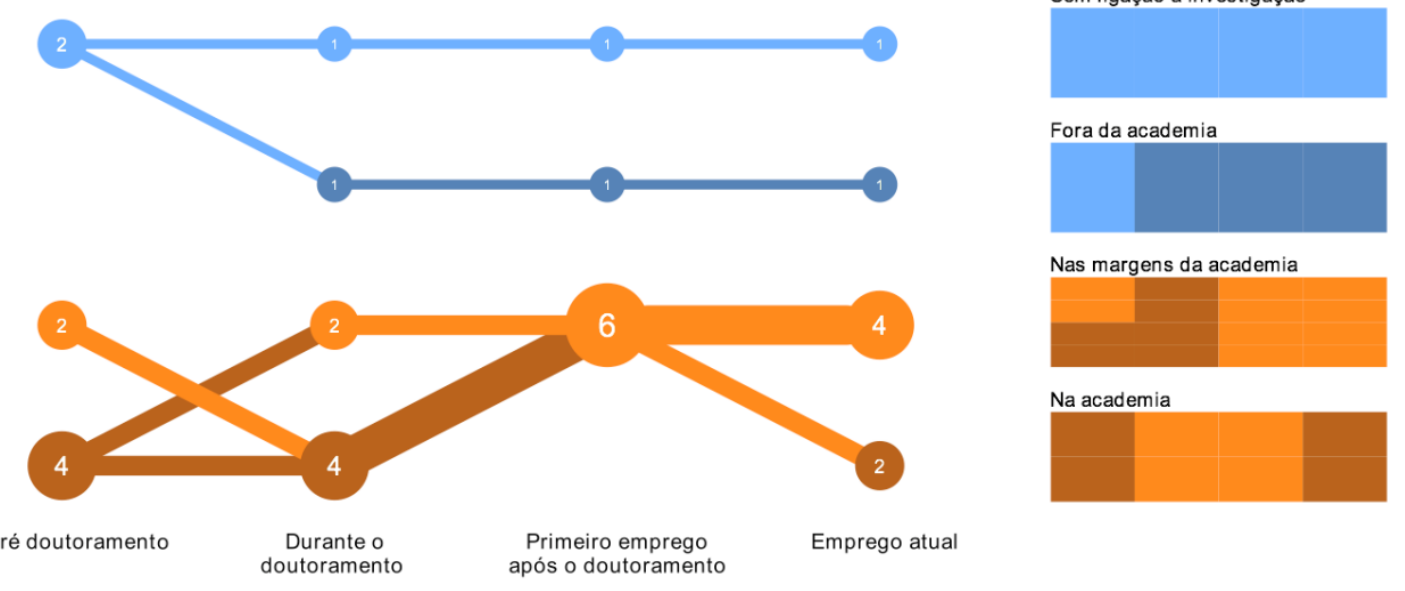

Figura 4a: Transições entre etapas da carreira das pessoas respondentes de Humanidades. Fonte: Inquérito por questionário
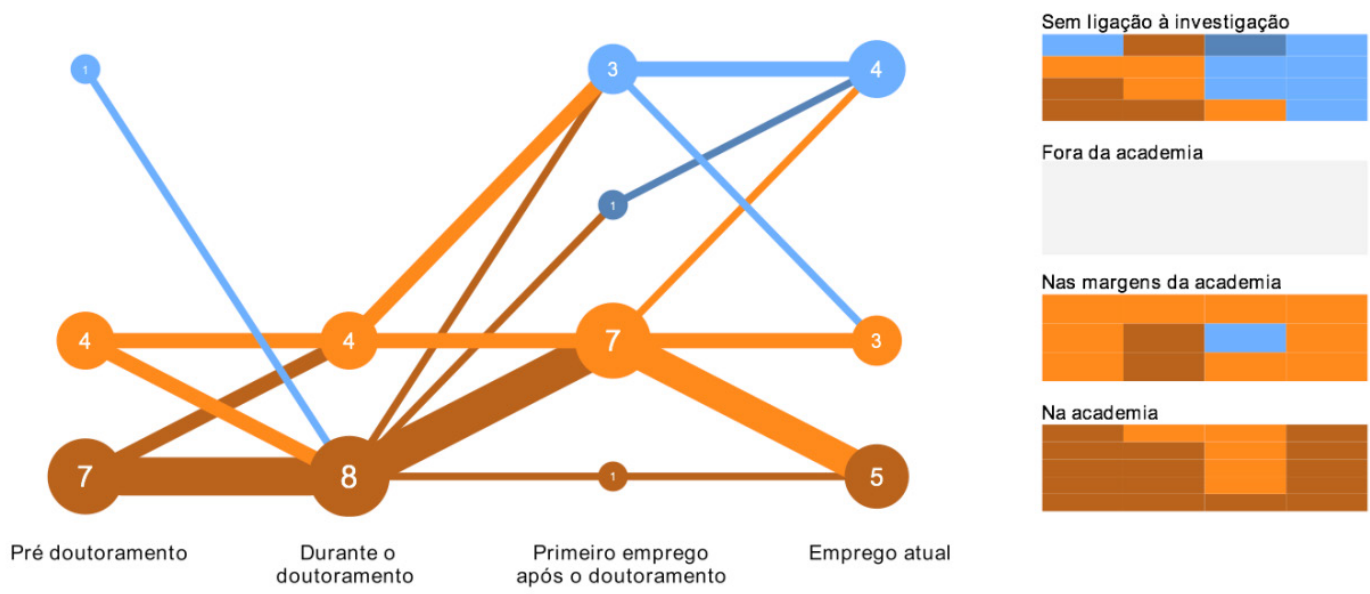

Fora da academia

Nas margens da academia

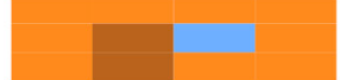

Na academia

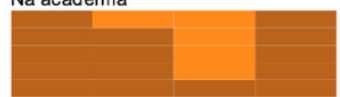

Figura 4b: Transições entre etapas da carreira das pessoas respondentes de Ciências Sociais. Fonte: Inquérito por questionário 


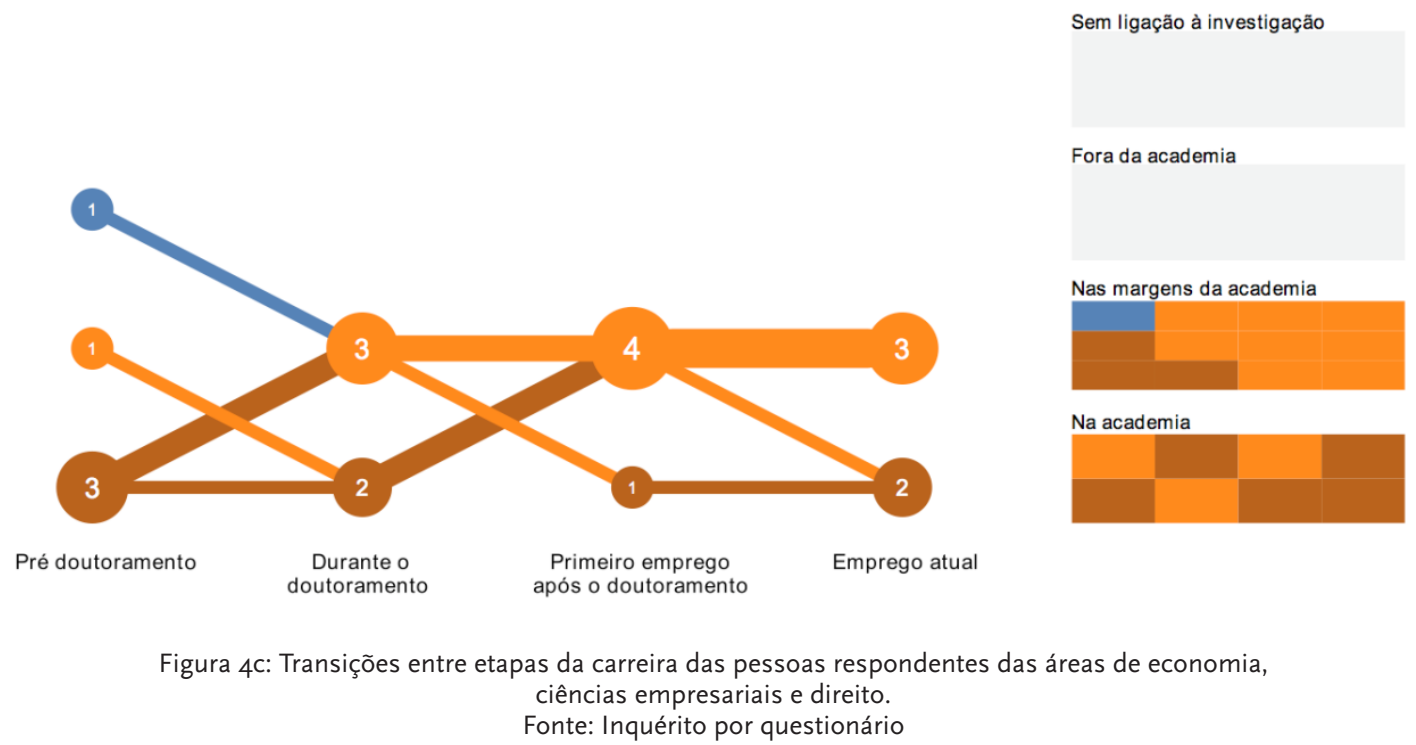

A análise das entrevistas permite compreender melhor as trajetórias profissionais e as respetivas dinâmicas internas. A aprendizagem e o estabelecimento de redes de contatos, entre outros, parecem ser relevantes para compreender a construção dos percursos profissionais. Para uma parte das pessoas com doutoramento, o interesse pela investigação surgiu durante o mestrado ou durante o próprio doutoramento. Mas, perante a incerteza da empregabilidade no meio académico, uma parte considerável foi obrigada a repensar a sua carreira. Contudo, não foram muitas as que mudaram de sector ou que revelassem estar preparadas para trabalhar noutro âmbito.

Não sei se tenho futuro nesta carreira universitária, uma vez que atingimos um ponto em que a estabilidade está ameaçada. Existe uma ameaça de dispensa de funcionários públicos e de cortes no Estado social. Por isso, não sei como será o futuro.

P: Faz parte dos seus planos mudar de sector?

R: Não, não faz parte dos meus planos. A universidade foi a minha opção. Se quisesse sair, já teria saído e começado uma carreira na política. (...) De outra forma, não existe nenhuma hipótese de mudar de sector. (...) Não vejo outras oportunidades de mudar de sector na conjuntura atual. E penso não ser o único nesta situação. (PT1 - no meio académico, homem, 45 anos)

Tal como afirmado por outro entrevistado, devido às limitações do mercado de trabalho atual, e também aos problemas de reconhecimento de competências, a mobilidade entre sectores pode ser fácil noutros locais, mas não em Portugal:

(...) De vez em quando penso "E se...", mas não há muitas alternativas para mudanças. Em primeiro lugar, porque as oportunidades de trabalho não permitem uma transição fácil neste momento. Em segundo lugar, porque tenho noção das minhas competências e sei do que sou capaz, mas não 
acho que as outras pessoas sejam capazes de olhar para um professor do ensino superior e perceber o seu potencial noutras áreas que não o ensino. Por isso, penso que, em Portugal, não é fácil para um professor do ensino superior mudar de sector. Em qualquer outro lado, é. (PT2O - no meio académico, homem, 41 anos)

\section{Discussão E CONCLUSÃo}

Este artigo analisa o percurso académico de pessoas doutoradas em CSH em Portugal. Em termos gerais, confirma o facto de a maioria dos doutoramentos preparar as pessoas designadamente para uma carreira académica. No entanto, constata-se que apenas $36 \%$ destas pessoas doutoradas alcançaram uma posição estável no meio académico. Vários anos após a conclusão do grau, outras $40 \%$ ou permaneciam em postos de trabalho de natureza instável na academia ou estavam nas margens desse meio. Cerca de um quarto (24\%) tinham-se fixado em atividades não relacionadas com a investigação ou na investigação fora do contexto académico. Durante o doutoramento, parte das pessoas entrevistadas acalentou a expetativa de vir a fazer carreira no meio académico mas, após a conclusão do grau, confrontou-se com a realidade do mercado laboral. Um número significativo permaneceu em empregos instáveis, embora outros/ as tenham alcançado, de forma progressiva, uma maior estabilidade académica. Outras procuraram atividades de investigação fora do meio académico ou abandonaram completamente a investigação. Não se registam diferenças significativas entre mulheres e homens com doutoramento em CSH. Observam-se, em contrapartida, diferentes padrões entre as áreas científicas. As expetativas são mais elevadas nas Ciências Sociais do que nas Humanidades. Nas primeiras, são também mais evidentes na Economia, Ciências Empresariais e no Direito, em comparação com as restantes. Seria de todo o interesse haver mais investigação neste domínio de modo a estudar as trajetórias profissionais, o sucesso na carreira e a satisfação no trabalho (Canal \& Wall, 2014) noutras áreas científicas.

Tendo-se constatado que não há muitas pessoas a passarem por processos de mudança sectorial, uma investigação mais aprofundada permitira compreender como as pessoas doutoradas em CSH se movem fora da academia - se estabelecem relações fora do meio académico (Mangematin, 2000), por exemplo, através de acordos com entidades parceiras públicas ou privadas - e, ainda, como gerem as suas aprendizagens em diferentes contextos profissionais.

\section{REFERÊNCIAS BIBLIOGRÁFICAS}

Ackers, L. \& Gill, B. (2008). Moving people and knowledge. Scientific mobility in an enlarging European Union. Edward Elgar: Cheltenham.

Auriol, L. (2010). Careers of doctorate holders: Employment and mobility patterns. Science, Technology and Industry Working Papers, 4. Retirado de http://dx.doi.org/10.1787/5kmh8phxvvf5-en. 
Auriol, L.; Misu, M. \& Freeman, R. A. (2013). Careers of Doctorate Holders: Analysis of Labour Market and Mobility Indicators. Science, Technology and Industry Working Papers. Retirado de http://dx.doi. org/10.1787/5k43nxgs28gw-en.

Barnacle, R. \& Dall'Alba, G. (2011). Research degrees as professional education? Studies in Higher Education, $36(4), 459-470$

Brailsford, I. (2010). Motives and aspirations for doctoral study: Career, personal, and inter-personal factors in the decision to embark on a History PhD. International Journal of Doctoral Studies, 5, 15-27.

Calmand J. \& Giret J.-F. (2010). L'Insertion des docteurs: Enquête Génération 2004, interrogation 2007. Retirado de http://www.cereq.fr/index.php/ publications/L-insertion-des-docteurs-Enquete-Generation-2004--Interrogation-2007.

Canal-Domínguez, J. F. \& Wall, A. (2014). Factors determining the career success of doctorate holders: evidence from the Spanish case. Studies in Higher Education, 39(10), 1750-1773.

Cañibano Sánchez, C., Otamendi, F.J. \& Solís, S. (2011). International temporary mobility of researchers: a cross-discipline study. Scientometrics, 89(2), 653-675.

Cheung, C.; Guillemette, Y. \& Mobasher-Fard, S. (2012). Tertiary education: Developing skills for innovation and long-term growth in Canada. OECD Economics Department Working Papers, 991. Retirado de http:// www.oecd-ilibrary.org/docserver/download/5k92pghq4247.pdf?expires=1461705338\&id=id\&accname=g uest\&checksum=E620BAF8439DF812009DA98E997EE5AC.

Comissão Europeia. (2011). Supporting Growth And Jobs - An Agenda for the Modernisation of Europe's Higher Education Systems. Retirado de http://eur-lex.europa.eu/LexUriServ/LexUriServ. do?uri=COM:2011:0567:FIN:EN:PDF

Cruz Castro, L. \& Sanz Menéndez, L. (2005). The employment of PhDs in firms: trajectories, mobility and innovation. Research Evaluation, 14(1), 57-69.

Cyranoski, D., Gilbert, N., Ledford, H., Nayar, A. \& Yahia, M. (2011). Education: The PhD factory. Nature, 472, 276-279.

Fox, M. \& Stephan, P. (2001). Careers of young scientists: preferences, prospects and realities by gender and field. Social Studies of Science, 31 (1), 101-122.

Fritsch, M. \& Krabel, S. (2012). Ready to leave the ivory tower? Academic scientists appeal to work in the private sector. Journal of Technology Transfer, 37(3), 271-296.

Guerin, C.; Jayatilaka, A. \& Ranasinghe, D. (2014). Why start a higher degree by research? An exploratory factor analysis of motivations to undertake doctoral studies. HERDSA - Higher Education Research $Q$ Development, 34(1), 89-104.

Herrera, L.; Munoz-Doyague, M. \& Nieto, M. (2010). Mobility of public researchers, scientific knowledge transfer and the firm's innovation process. Journal of Business Research, 63(5), 510-518.

Horta, H. (2009). Holding a post-doctoral position before becoming a faculty member: does it bring benefits for the scholarly enterprise? Higher Education, 58(5), 689-721.

Huisman, J.; Weert, E. \& Bartelse, J. (2002). Academic careers in Europe. The declining desirability of the faculty position. Journal of Higher Education, 73(1), 141-160.

Lee, H.; Miozzo, M. \& Laredo, P. (2010). Career patterns and competences of PhDs in science and engineering in the knowledge economy: The case of graduates from a UK research-based university. Research Policy, 39, 869-881. 
Leonard, D.; Becker, R. \& Coate, K. (2005). To prove myself at the highest level: The benefits of doctoral study. Higher Education Research Q Development, 24(2), 135-149.

Mangematin, V. (2000). PhD job market: professional trajectories and incentives during the PhD. Research Policy, 29(6), 741-756.

Stephan, P. \& Levin, S. (1997). The critical importance of careers in collaborative scientific research. Revue D'Économie Industrielle, 79, 45-61.

Thune, T. (2009). Doctoral students on the university-industry interface: a review of the literature. Higher Education, 58, 637-651.

Vinck, D. (1996). The dynamics of scientific intellectuals within the integrative trend in Europe: the case of cooperation networks. In A. Elzinga \& C. Lanström (Eds.), Internationalism and Science (pp.162-198). London: Taylor Graham.

Yerkes, M.; van de Schoot, R. \& Sonneveld, H. (2012). Who are the job seekers? Explaining unemployment among doctoral recipients. International Journal of Doctoral Studies, 7, 153-166.

Zellner, C. (2003). The economic effects of basic research: evidence for embodied knowledge transfer via scientists' migration. Research Policy, 32 (10), 1881-1895.

\section{Agradecimentos}

Este artigo baseia-se numa investigação financiada pelo sétimo programa-quadro de apoio a projetos de investigação, da União Europeia, no âmbito do projeto POCARIM (Mapping the Population, Careers, Mobilities and Impacts of Advanced Research Degree Graduates in Social Sciences and Humanities (http://www.liv.ac.uk/lawandsocialjustice/ research/pocarim/). O nosso agradecimento particular a Andréas Perret pelo design visual e processamento de dados com recurso ao Gephi e ao TraMineR.

\section{NOTAS BIOGRÁFICAS}

Heloísa Perista é socióloga e investigadora sénior no CESIS - Centro de Estudos para a Intervenção Social. As suas áreas de interesse e investigação incluem: igualdade de género, usos do tempo e articulação trabalho-família, condições de trabalho, carreiras de investigação científica, envelhecimento, violência de género e direitos humanos. Assegura as funções de ponto focal nacional em Portugal da FRANET, no âmbito da FRA - Agência dos Direitos Fundamentais da União Europeia; e do EurWORK - European Observatory of Working Life e do EMCC - European Monitoring Centre on Change, no âmbito da Eurofound - Fundação Europeia para a Melhoria das Condições de Vida e de Trabalho.

E-mail: heloisa.perista@cesis.org

CESIS - Centro de Estudos para a Intervenção Social, Av. 5 de Outubro, $n^{\circ} 12-4^{\circ}$ Esq.-Lisboa - Portugal 
Pedro Perista é sociólogo e investigador no CESIS - Centro de Estudos para a Intervenção Social e co-coordenador da secção de Pobreza, Exclusão Social e Políticas Sociais da Associação Portuguesa de Sociologia. Para além da participação em projetos de âmbito nacional e internacional representa, actualmente, Portugal na Rede Europeia de Política Social e em diferentes redes de peritos para a avaliação do Fundo Social Europeu. Assegura ainda a função de perito em questões sociais no âmbito da equipa ponto focal nacional em Portugal da FRANET, no âmbito da FRA - Agência dos Direitos Fundamentais da União Europeia. Recentemente co-organizou a publicação Pobreza $e$ exclusão social em Portugal: contextos, transformações e estudos (Húmus, 2015).

E-mail: pedro.perista@cesis.org

CESIS - Centro de Estudos para a Intervenção Social, Av. 5 de Outubro, $n^{\circ} 12-4^{\circ}$ Esq.-Lisboa - Portugal

Dominique VINCK é professor catedrático na Universidade de Lausane (UNIL). É membro do Instituto de Ciências Sociais e diretor do Laboratório de culturas digitais e Humanidades (LaDHUL). As suas investigações tem-se centrado nos estudos da ciência e da inovação. Atualmente trabalha nas temáticas da engenharia de culturas digitais e Humanidades. É diretor da Revue d'Anthropologie des Connaissances (http://www.cairn. info/revue.php?ID_REVUE=RAC). Entre outras publicações, destacam-se as seguintes: Everyday engineering, An ethnography of design and innovation (MIT Press, 2003), The Sociology of Scientific Work. The Fundamental Relationship between Science and Society (E. Elgar, 2010), L'équipement de l'organisation industrielle. Les ERP à l'usage (Hermes, 2008), Comment les acteurs s'arrangent avec l'incertitude (EAC, 2009), Les Masques de la convergence (EAC, 2012), Ingénieurs d'aujourd'hui (PPUR, 2015), Sciences et technologies émergentes. Pourquoi tant de promesses? (Hermann, 2015).

E-mail: dominique.vinck@unil.ch

Institut des Sciences Sociales - Geopolis, Université de Lausanne, CH- 1015, Lausanne, Switzerland

* Submetido: 16-11-2015

* Aceite: 20-11-2015 